Научная статья

УДК 821.161 .1

doi: 10.18101/2305-459X-2021-1-42-47

\title{
ИНТЕРПРЕТАЦИЯ БИБЛЕЙСКОГО ТЕКСТА В РОМАНЕ М. А. БУЛГАКОВА «МАСТЕР И МАРГАРИТА»
}

\author{
(C) Колмакова Оксана Анатольевна \\ доктор филологических наук, доцент, \\ Бурятский государственный университет имени Доржи Банзарова \\ Россия, 670000, г. Улан-Удэ, ул. Смолина, 24а \\ post-oxygen@mail.ru \\ (C) Боброва Анастасия Олеговна \\ магистрант, \\ Бурятский государственный университет имени Доржи Банзарова \\ Россия, 670000, г. Улан-Удэ, ул. Смолина, 24а \\ bobrovanast@mail.ru
}

\begin{abstract}
Аннотация. В структуре романа М. А. Булгакова «Мастер и Маргарита» важное место занимает библейский текст. При этом проблема его трактовки в литературоведении остается дискуссионной. В свете христианской концепции русской классической литературы и культуры в целом роман Булгакова не может быть однозначно интерпретирован как апологетический по отношению к христианству. Символическое содержание образов и мотивов романа, имеющих в своей основе библейские архетипы и модели, а также общий стилистический «библейский фон» повествования в ершалаимских главах не отвечают в полной мере христианской ментальности и системе ценностей. Библейский текст получает неоднозначную и зачастую амбивалентную трактовку, что позволяет считать автора романа не религиозным философом, а прежде всего художником.
\end{abstract}

Ключевые слова: М. А. Булгаков; «Мастер и Маргарита»; библейский текст; образ; архетип; мотив.

\section{Для цитирования}

Колмакова O. А., Боброва A. О. Интерпретация библейского текста в романе М. А. Булгакова «Мастер и Маргарита» // Вестник Бурятского государственного университета. Язык. Литература. Культура. 2021. Вып. 1. С. $42-47$.

Одной из актуальных проблем отечественного литературоведения остается изучение библейского текста русской литературы. Обращение русских писателей к Библии имеет давнюю традицию. Рассматривая роль Священного Писания в древнерусской повести, Е. К. Ромодановская говорит о «прямом заимствовании библейского сюжета и переделке его в повесть», а также о «создании нового произведения на основе стиха из Псалтыря или Евангелия, когда текст Писания делается главным сюжетообразующим элементом» [4, с. 67].

В романе «Мастер и Маргарита» М. А. Булгаков использует обе обозначенные исследователем тенденции. Роман о Пилате написан Мастером на основе заимствованного из Евангелия сюжета о суде и распятии Иисуса Христа. Также 
O. А. Колмакова, А. О. Боброва. Интерпретация библейского текста в романе М. А. Булгакова «Мастер и Маргарита»

библейские корни имеет сюжет путешествия дьявола по земле. Ср.: «И сказал Господь сатане: откуда ты пришел? И отвечал сатана Господу, и сказал: я ходил по земле и обошел ее» (Иов, 2: 1-2). Если в Библии происходит прямой диалог между Богом и дьяволом, то у Булгакова этот диалог опосредован участием Левия Матвея.

Как элемент библейского текста в романе Булгакова присутствует соответствующая символика, в частности, символика солнечного и лунного света. Лунный свет выступает теневым «двойником» солнечного. С одной стороны, «стень», «темная суть», «студеньство нощное», с другой - солнце, свет, «солнечьнеи теплоте» $[4$, с. 221$]$. Возникает оппозиция ложного, обманчивого света и света истинного, благодатного. У Булгакова оба небесных светила становятся важными образами романа.

Солнце - устойчивый библейский символ жизни, радости, подлинного света Истины - сопровождает Иешуа на крестном пути. Луна символизирует враждебный мир теней, загадок, призрачности. В романе лунный свет - это не только царство Воланда и его гостей, пирующих в полнолуние на весеннем балу, но и холодеющий свет успокоения и вечного сна. Будучи немыми свидетелями событий в Ершалаиме и Москве, оба светила символизируют единство времен, непрерывность человеческой истории.

Вместе с тем поэтику «Мастера и Маргариты» можно назвать «лунной»: луна в тексте упоминается 83 раза, в то время как солнце - 48 раз. Примечательно то, что луна в романе пребывает в полном одиночестве. Вечные ее спутники, звезды, встречаются лишь однажды в образе шпор Воланда: «Воланд летел... в своем настоящем обличье... повод его коня... это лунные цепочки и самый конь только глыба мрака, и грива этого коня - туча и шпоры всадника - белые пятна звезд» $[1$, с. 745$]$. Можно с полным правом сказать, что луна у Булгакова имеет амбивалентную символику, которая проявляется в том, что лунный свет становится индикатором истинного и ложного. При свете луны происходит преображение «князя мира сего» и его свиты.

Образы луны и солнца раскрывают в романе мотив деформации жизни. Приведем примеры: «Иностранец <..> остановил взор на верхних этажах, ослепительно отражающих в стеклах изломанное и навсегда уходящее от Михаила Александровича солнце» [1, с. 383]; «Берлиоз упал навзничь... и успел увидеть в высоте, но справа или слева - он уже не сообразил, - позлащенную луну.... Тут в мозгу у Берлиоза кто-то отчаянно крикнул — "Неужели?.." Еще раз, и в последний раз, мелькнула луна, но уже разваливаясь на куски, и затем стало темно» [1, с. 418-419].

Булгаковская символика луны и солнца связана также с идеей зависимости жизни человека от трансцендентного мира. Для Маргариты, королевы бала сатаны, нет лучшей подруги, чем луна, которая будет «со свистом омывать тело», «приятно согревать». «Раскаленный шар солнца» будет мучить, вызывать головную боль у Понтия Пилата, человека с нечистой совестью.

Библейская стилистика в романе Булгакова проявляется в том, как развиваются его главные, «вечные» темы: борьбы добра и зла, света и тьмы, небесного и земного. В романе мир делится на две стихии - «удел света» и «удел мрака», а 
история Пилата является обрамлением к повествованию о похождениях свиты Воланда в Москве. Персонажи воландовой свиты не похожи на демонов в их традиционном изображении. Эти «злые духи» не отделены от Бога и от человека. Единственный традиционно-демонический мотив, связанный с Воландом и его свитой у Булгакова, - это безумие. Мотив безумия получает в романе вполне христианское обоснование: безумие - от дьявола. В результате «похождений» Коровьева-Фагота, Кота-Бегемота и Азазелло происходит увеличение числа пациентов психиатрической клиники профессора Стравинского.

Тема бесовства оборачивается в романе темой маскарада, игры. Ни один из инфернальных героев не предстает до поры до времени в своем истинном виде. Эти герои играют роли, тщательно скрывающие их внутреннюю сущность. Вспомним, к примеру, о первом появлении Коровьева: «И тут знойный воздух сгустился перед ним, и соткался из этого воздуха прозрачный гражданин престранного вида. На маленькой головке жокейский картузик, клетчатый кургузый воздушный же пиджачок... Гражданин ростом в сажень, но в плечах узок, худ непомерно, и физиономия, прошу заменить, глумливая» [1, с. 380].

Какие только маски не примерит этот «клетчатый»: он будет и «неизвестным плаксой», и «втирушей-регентом», и «поганым Фаготом». И лишь в последней главе мы узнаем, кто на он на самом деле. «На месте того, кто в драной цирковой одежде покинул Воробьевы горы под именем Коровьева-Фагота, теперь скакал, тихо звеня золотою цепью повода, темно-фиолетовый рыцарь с мрачнейшим и никогда не улыбающимся лицом» [1, с. 744]. Только в своем кругу персонажи воландовой свиты расстаются с масками. Потому-то и слышат случайные визитеры «нехорошей квартирки» обращения типа «мессир» или «рыцарь».

В романе присутствует еще один важный библейский мотив - мотив «чаши жизни», связанный с символикой «страшного суда». «- Вы уходите в небытие, и мне радостно будет из чаши, в которую вы превратитесь, выпить за бытие» $[1$, c. 642], — обращается Воланд к голове Берлиоза. «Живой водой» для Воланда становится человеческая кровь, которая проливается во искупление. Человек у Булгакова не наделяется «наследством вечным» (материалист Берлиоз уходит в небытие), но его грех уже искуплен, и кровь, хотя и неправедная, даст живительные всходы, которые будут нести другим то, что не могли дать сами погибшие.

Мотив крови один из сквозных в романе. «Кровавый подбой» плаща прокуратора Иудеи свидетельствует как о крови, пролитой ранее, так и о крови, которая еще прольется. Кровь проливается там, где находится Воланд и его свита, будь то кровь обезглавленного конферансье или же кровавые царапины на голове буфетчика. Писатель создает фантасмагорийную картину жизни, где разрушается все святое и творятся кровавые дела. Тревожные образы-символы грозы, пожара передают катастрофическое состояние окружающего мира. И все же «темным силам» в романе противостоят люди с чистой душой, несущие любовь и красоту.

Наконец, элементами библейского текста в романе М. А. Булгакова становятся образы-архетипы Священного Писания. Понтий Пилат как библейский архетип интересует автора в связи с темой трусости, за которую герой несет суровое наказание: «Около двух тысяч лет... его терзает бессонница... а когда спит, то видит одно и то же - лунную дорогу, и хочет пойти по ней и разговаривать $\mathrm{c}$ 
О. А. Колмакова, А. О. Боброва. Интерпретация библейского текста в романе М. А. Булгакова «Мастер и Маргарита»

арестантом Га-Ноцри... Но, увы, ему выйти на эту дорогу почему-то не удается» $[1$, c. $746-747]$.

С образом струсившего Пилата Булгаков мог встретиться в романе французского писателя Э. Ренана «Жизнь Иисуса» (1863). Пилат Ренана со страхом размышляет о том, как он «как бы наперед прочел донос, который его враги могли бы послать в Рим и где его обвинили бы в том, что он поддерживал соперника Тиберия» [9, с. 258]. У Булгакова страх Пилата усиливается ужасным видением «плешивой головы... в редкозубом золотом венце» - головы императора, надменно тянущего слова: «Закон об оскорблении величества» [1, с. 401].

Булгаковский Пилат более «человечен», чем ренановский, не говоря уже о евангельском. Булгаков изображает, как смертельно больной человек, помышляющий о яде, ненавидящий город и его жителей, презирающий закон за его жестокость, испугался всего лишь потери своей должности. Тогда-то и совершает Пилат свой грех - поддается трусости. Примечательно, что тема трусости занимала самого Булгакова. В. Виленкин приводит один из своих разговоров с писателем:

«- Скажите, какой человеческий порок, по-вашему, самый главный? спросил он меня однажды совершенно неожиданно. Я стал в тупик и сказал, что не знаю, не думал об этом.

- А я знаю. Трусость - вот главный порок, потому что от него идут все остальные» [3, с. 528].

Сочувствие, проявленное к бродячему философу Га-Ноцри, смягчает грех Пилата. Поэтому Мастер не помещает своего героя в ад, наказание Пилата напоминает чистилище, хотя, по мнению И. Есаулова, «православное сознание отвергает идею чистилища как промежуточной самостоятельной субстанции» [4, с. 54]. Искупление Пилата длится «двенадцать тысяч лун».

Булгаков обращается и к архетипу блудного сына - одному из наиболее часто используемых в мировой художественной культуре. Соотнося судьбу героя с архетипом блудного сына, художник полагает, что эволюция человека индивидуальна и осуществляется через самоуглубление и постижение вечных, объективно существующих и потому неизменных законов бытия, знание которых растрачивается человеком во время скитания его по «морю житейскому». В основе сюжета художественных произведений о блудном сыне лежат мотивы испытаний с последующим возвращением к истоку: изменившийся герой обретает себя, возвращается к себе.

К библейскому архетипу восходят образы двух булгаковских «блудных сыновей». Один из них - Иван Бездомный. Как пишет В. Я. Петелин, «клиника профессора Стравинского - один из вариантов столь любимого писателем мотива дома-убежища, единственное место на этой земле, где уготовано спасение» $[8$, c. 60]. О том, какой дом обрел Иван Бездомный и какое спасение он нашел, можно строить множество догадок. Но все же лучше всего нам об этом поведал сам автор: «сотрудник Института истории и философии, профессор Иван Николаевич Понырев... он все знает и понимает» [1, с. 749].

В снах Ивана Бездомного мы встречаем еще одного возвратившегося к себе «блудного сына», Понтия Пилата. Пилат приходит к свету сквозь «двенадцать 
тысяч лун» и обретает прощение безвинно казненного им бродячего философа Иешуа Га-Ноцри.

Однако в романе Булгакова «преображения» происходят не только с Иваном Бездомным и Понтием Пилатом. «Жорж, например, Бенгальский... ушел на покой и начал жить на свои сбережения, которых ему, по его скромному подсчету, должно было хватить на пятнадцать лет» [1, с. 756]. Степу Лиходеева «перебросили в Ростов, где он получил назначение на должность заведующего большим гастрономическим магазином. Ходят слухи, что он перестал пить портвейн и пьет только водку, настоянную на смородиновых почках, отчего очень поздоровел. Говорят, что стал молчалив и сторонится женщин» [1, с. 756]. А вот Аркадия Аполлоновича Семплеярова «в два счета перебросили в Брянск и назначили заведующим грибозаготовочным пунктом» [1, с. 757].

В стремительности изменений, происходящих с героями, проглядывает нечеловеческий промысел. Одна из ключевых христианских идей состоит в том, что дистанция между праведниками и грешниками в действительности ничтожна, что перед Богом равны все, а потому все достойны божественного участия. Coгласно христианскому канону, надежда на преображение и прозрение не может быть отнята, пока самый закоренелый грешник еще жив. И все же приведенные эпизоды отчетливо гротескны и дают повод сомневаться в истинности духовного преображения, скрытого за «физикой» произошедших с героями изменений.

Итак, в романе М. А. Булгакова «Мастер и Маргарита» библейский текст реализуется практически на всех уровнях поэтики и проблематики - цитатном, символическом, архетипическом, сюжетном. Амбивалентная символика библейских образов и мотивов говорит о приоритетности для Булгакова нравственноэстетических, а не религиозно-этических художественных задач.

Литература

1. Булгаков М. А. Пьесы. Романы / составление, вступительная статья и примечание В. М. Акимова. Москва: Правда, 1991. 768 с. Текст: непосредственный.

2. Вайскопф М., Толстая Е. Москва под ударом, или Сатана на Тверской: «Мастер и Маргарита» и предыстория мифопоэтики «московского текста» // Литературное обозрение. 1994. № 3/4. С. 87-90. Текст: непосредственный.

3. Виленкин В. Незабываемые встречи // Булгаков М. А. Я хотел служить народу. Москва: Педагогика, 1991. С. 658-675. Текст: непосредственный.

4. Евангельский текст в русской литературе XVII-XX веков: цитата, реминисценция, мотив, сюжет, жанр: сборник научных трудов / ответственный редактор В. Н. Захаров. Петрозаводск: Изд-во Петрозавод. ун-та, 1994. 388 с. Текст: непосредственный.

5. Коган Л. Н. Иисус и Понтий Пилат. Три интерпретации одного «вечного» сюжета // Философская и социальная мысль. 1990. № 9. С. 46-53. Текст: непосредственный.

6. Кораблев А. Тайнодействие в «Мастере и Маргарите» // Вопросы литературы. 1991. № 5. С. 35-54. Текст: непосредственный.

7. Макарова Г., Абракшин А. Откуда взялась банда Воланда // Молодая гвардия. 1994. № 7. С. 225-234. Текст: непосредственный.

8. Петелин В. Я. Родные судьбы. Москва: Современник, 1976. 400 с. Текст: непосредственный.

9. Ренан Э. Ж. Жизнь Иисуса. Москва: Политиздат, 1991. 398 с. Текст: непосредственный. 
О. А. Колмакова, А. О. Боброва. Интерпретация библейского текста в романе М. А. Булгакова «Мастер и Маргарита»

10. Яблоков Е. А. Художественный мир Михаила Булгакова. Москва: Языки славянской культуры, 2001. 424 с. Текст: непосредственный.

Статья поступила в редакиию 29.01.2021; одобрена после рецензирования 24.02.2021; принята к публикации 05.03.2021.

\title{
INTERPRETATION OF THE BIBLICAL TEXT IN MIKHAIL BULGAKOV'S NOVEL "THE MASTER AND MARGARITA"
}

Oksana A. Kolmakova

Dr. Sci. (Phil.), A/Prof.,

Dorzhi Banzarov Buryat State University

24a Smolina St., Ulan-Ude 670000, Russia

E-mail: post-oxygen@mail.ru

\author{
Anastasia O. Bobrova \\ Master's Student, \\ Dorzhi Banzarov Buryat State University \\ 24a Smolina St., Ulan-Ude 670000, Russia \\ E-mail: bobrovanast@mail.ru
}

Abstract. The biblical text occupies an important place in the structure of Mikhail Bulgakov's novel "The Master and Margarita". Nevertheless, the problem of its interpretation in literary criticism remains controversial. From the perspective of the Christian concept of Russian classical literature and culture, Bulgakov's novel cannot be unambiguously interpreted as apologetic in relation to Christianity. Symbolism of the characters and motives in the novel, which are based on biblical archetypes, as well as the general stylistic "biblical background" of the narrative in the Yershalaim chapters, do not fully correspond to the Christian mentality and value system. The biblical text has an ambiguous and often ambivalent interpretation, and this allows us to conceive of the author not as a religious philosopher, but primarily as an artist.

Keywords: Mikhail Bulgakov; "The Master and Margarita"; biblical text; character; archetype; motive.

\section{For citation}

Kolmakova O. A., Bobrova A. O. Interpretation of the Biblical Text in Mikhail Bulgakov's Novel "The Master and Margarita". Language. Literature. Culture. 2021; 1: 42-47 (In Russ.).

The article was submitted 27.01.2021; approved after reviewing 18.02.2021; accepted for publication 05.03.2021. 